This document is the accepted manuscript version of the following article:

Lienert, J., \& Larsen, T. A. (2007). Pilot projects in bathrooms: a new challenge for wastewater professionals. Water Practice and Technology, 2(3), 1-14.

https://doi .org/10.2166/wpt.2007.057

\title{
PILOT PROJECTS IN BATHROOMS: A NEW CHALLENGE FOR WASTEWATER PROFESSIONALS
}

\author{
Judit Lienert*, Tove A. Larsen
}

Eawag

Swiss Federal Institute of Aquatic Science and Technology

Dept. Urban Water Management

Ueberlandstrasse 133

P.O. Box 611

$\mathrm{CH}-8600$ Duebendorf

Switzerland

* Corresponding author: Judit Lienert, judit.lienert@eawag.ch

Tel: +41 4482355 74, Fax: +41448235389

Both authors are co-project managers of the cross-cutting project Novaquatis

\begin{abstract}
Household-centered technologies such as urine source separation (NoMix technology) could induce a paradigm change in urban wastewater management, hereby improving water pollution control and resource management. Technological innovations need real-world application for further development. The Swiss research project Novaquatis accompanied five pilot projects from 1997 on. We give a systematic overview of our experience, summarizing various important aspects, a fundamental one being a clearly defined goal. Early stakeholder involvement is crucial, because the still imperfect NoMix technology depends on people's goodwill. We reference data sheets, legal documents, etc. and make suggestions for installation, maintenance, and technology improvement. We identify areas for future research necessitating pilot projects and discuss their requirements to optimize the cost-benefit factor. This paper is intended as support to wastewater professionals to avoid the most serious pitfalls when conducting NoMix pilot projects. It contributes to increased interaction between research and real-world application of urban European household innovations.
\end{abstract}

\section{INTRODUCTION}

Urine source separation (NoMix technology) is receiving increasing interest from wastewater engineers in science and practice around Europe. The technology is intuitively attractive, allowing for nutrient recycling and the introduction of additional source control measures to urban wastewater management (e.g., 1-4). Innovations need testing and improvement in the real-world, and pilot projects are essential to gain experience and further develop the technology (5). For wastewater engineers who are used to working at treatment plants, NoMix pilot projects are demanding. They are associated with risks because they enter private bathrooms and involve close cooperation with people using this novel sanitary technology in daily life. Since innovations can never be developed to full maturity in the laboratory, NoMix toilets do not yet meet the high standards of conventional sanitation, further increasing the risks of such projects. 
In the Swiss research project Novaquatis (www.novaquatis.eawag.ch), a number of projects concerning NoMix technology were carried out, including pilot projects. A main objective of NoMix pilot projects is to give feedback to sanitary firms about improvements of the toilets. Novaquatis maintained good contacts with this industry. However, sanitary firms are reluctant to invest much money, as long as they do not see a large market (6). This market can only be created, if we can conduct large demonstration projects, which - again - is difficult because we have to install the still imperfect sanitary technology. Hence, we are caught in a vicious circle; the only way out is to conduct pilot projects as best as possible with the already available technology.

Novaquatis accompanied five NoMix pilot projects from 1997 on. We carried out one small project in households, which was also the most difficult one. All others were conducted in institutions (office buildings, college, public library), where maintenance is easier and acceptance seems to be higher. Nevertheless, both settings are needed, since they offer different learning possibilities. The purposes of the projects were manifold. We used them for extensive sociological research by conducting a focus group study (7) and quantitative surveys with 1750 users of NoMix toilets (8-9). We collected data on scaling, one of the most serious problems of NoMix toilets (10-11), and on tank filling (12). We needed urine for process engineering experiments (13-15) and micropollutant removal (16). Finally, we gained experience with practical aspects such as plumbing, maintenance, and toilet design. Since we are neither builders nor plumbers, we never intended to give advice on practical aspects, which was, however, often expected from us.

The pilot projects proved to be a core area of transdisciplinary science, with many stakeholders and disciplines involved. We gained insight into theoretical aspects of the real-world introduction of a technological innovation and also obtained considerable practical know-how. There is a growing interest by European wastewater professionals to conduct pilot projects with NoMix technology; we receive many requests from stakeholders hoping to profit from our experience. This paper is intended as overview of our know-how and summarizes various aspects - some trivial, some fundamental - that need to be considered by anyone conducting further NoMix pilot projects in an urban European environment.

\section{METHODS: THE PILOT PROJECTS}

All pilot projects were conducted in institutions, with one exception in private apartments. Three projects were conducted by third parties, who had a strong own motivation. We are carrying out two projects in our own office buildings at Eawag.

\section{Eawag Old and New Office Building}

The first NoMix toilet (www.wost-man-ecology.se) was installed in 1997 to collect data on precipitation (10-11). In 2000, two further toilets (www.dubbletten.nu) were installed near Eawag auditorium and cafeteria and connected to a storage tank. Sociological research showed that user acceptance was generally high, although the technological immaturity of NoMix toilets was noted especially by Eawag employees, while visitors were less critical $(7,9)$. The urine was used to develop process engineering technologies (13), including micropollutant removal (16), and we recorded the frequency of flushes to model urine occurrence (12). The new Eawag office building (opened 2006) is fully equipped with NoMix technology and allows larger scale testing (www.forumchriesbach.eawag.ch).

\section{Four Apartments in a Swiss German City}

Four apartments were equipped with Roediger NoMix toilets (www.roevac.com) in 2001 and connected to a storage tank in the cellar. The housing estate wanted to implement urine separation as part of their ecological building concept. Novaquatis scientifically accompanied the project; the 
wastewater authorities granted financial sponsoring. Our main goal was to assess social acceptance of NoMix toilets in private homes and test them in daily life. Again, data for modeling urine occurrence were collected (12). The initially difficult communication with tenants was improved by designating a single main contact person. The slightly negative attitude of some tenants was accentuated when two toilets revealed faulty ceramics in 2003. They were replaced with conventional toilets; in one apartment the child had difficulties to use the NoMix toilet, the other party was generally skeptical. The remaining tenants accepted the toilets fairly well. However, in 2005 all NoMix toilets were removed; one because of faulty ceramics, the other because of a malfunctioning urine outlet. Roediger has now improved the ceramics.

\section{Vocational / Design School in a Swiss German City}

The University of Applied Sciences Northwestern Switzerland (www.fhnw.ch) installed three types of NoMix toilets and six types of waterfree urinals in a college from 2002-2005. The main goal was to test different models and gain experience for the larger library project. Novaquatis assessed user acceptance, which was high; many people adopted the necessary behavior on NoMix toilets such as sitting to urinate (8-9). The NoMix toilets and waterfree urinals mainly functioned well. No blockages occurred after ca. 4000 usages of each model; however, they were regularly flushed with an acidic cleaner. Feedback from users and cleaners indicated that waterfree urinals might have an unpleasant odor, especially when not cleaned according to producers' recommendations. The collected urine had a low $\mathrm{N}$ - and P-content, possibly because of dilution, which we also observed in other pilot projects (12).

\section{Cantonal Library Basel-Landschaft in Liestal}

The wastewater authorities of canton Basel-Landschaft initiated a urine separation project in a public library (www.kbbl.ch) to test and optimize the NoMix technology (Fig. 1). This is the first Swiss pilot project with full implementation of NoMix technology and is worldwide one of the first projects demonstrating modern process engineering of urine on a semi-technical scale. The library opened in 2005, receiving considerable media attention. Urine from ca 200,000 visitors per year is transported by truck to an up-scaled processing unit. Urine is treated by a combination of electrodialysis and ozonation (15), which was chosen after lab-experimentation at Eawag (14). This treatment concentrates the nutrients, but removes the pharmaceuticals; the product is stable and hygienized. We received a provisional fertilizer allowance from the agricultural authorities to test the urine product in field experiments in 2006. Novaquatis also conducted sociological research over various age and social groups and questioned 501 people in 2005 . The feedback was generally positive; these data will be fully analyzed shortly.

\section{RESULTS AND DISCUSSION}

Some aspects of the NoMix technology are independent of the setting, others differ between user groups, public and private buildings. Requirements can differ between new constructions and older houses, where e.g., space is limited or piping difficult, which increases costs. An overview of the requirements is given in Tables $1-3$.

\section{Aspects to Consider before Building}

Aim of Pilot Project. It sounds trivial: The aim of the pilot project must be clear. We experienced that even wastewater professionals have difficulties to differentiate between general arguments for urine source separation and the goal of a specific pilot project. Nutrient removal to simplify wastewater treatment is appropriate in an entire catchment, and recycling of the limited resource phosphorus is a long-term goal of large-scale introduction of urine separation. However, in a small 

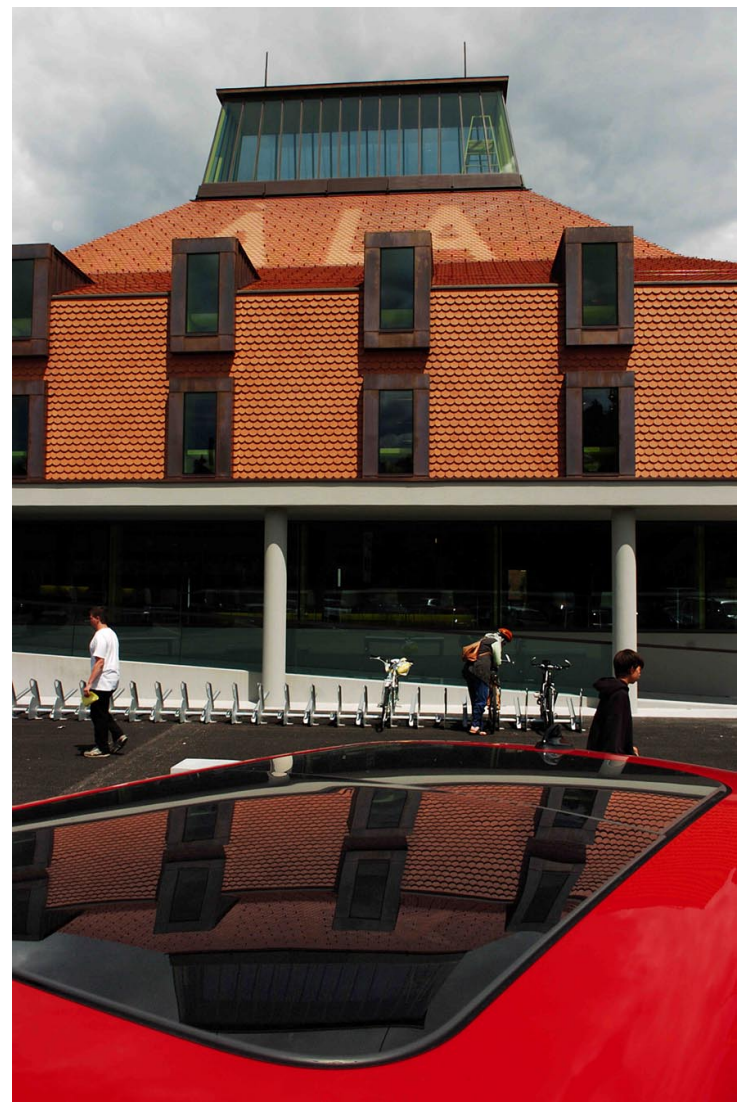

Figure 1. Cantonal library Basel-Landschaft in Liestal. This is the first Swiss building with full implementation of the NoMix technology. The urine from ca. 200,000 visitors per year is processed to a fertilizer product by a combination of electrodialysis and ozonation. Photo: Erwin Zbinden, 2006.

pilot project, most overall goals are not fulfilled. Pilot projects serve specific purposes, which are necessarily limited. We found it especially difficult to communicate that urine from a pilot project will not be used as fertilizer. Consequently, the wastewater authorities responsible for the library project insist that the urine is "applied" and use this argument in their communication strategy. Hence, in this project a main goal was to develop a urine process unit and receive a fertilizer allowance.

Ideally, a pilot project should not repeat work sufficiently described in the literature, but should render new information. We strongly recommend that NoMix pilot projects are supported by the wastewater authorities and accompanied by a clearly-defined research project. Stating explicit goals decreases the cost-benefit ratio and will also increase acceptance in the long run as compared to starting a project under false pretences.

Early Stakeholder Involvement. All stakeholders should be involved as early as possible and their consent to participate should be stipulated. We recommend sketching out all parties; it is surprising, how many are involved (Tab. 1). Architects, planners, and builders need to know beforehand that NoMix technology is installed, since many decisions differ from conventional buildings.

The imperfect NoMix technology strongly depends on the goodwill of all stakeholders to tolerate the daily trivial drawbacks, which can sum up to a real nuisance. If stakeholders can identify themselves with the project, it is less likely to fail. In our case study in apartments, only the housing estate owners, wastewater authorities, and scientists were involved from the beginning. This was a major mistake, because acceptance among inhabitants was low once the first small problems arose. Moreover, they were not aware that participating in a research project also meant that scientists would walk into their bathrooms, asking strange questions. 
Table 1. Overview of general aspects. These should be considered before building a NoMix pilot project.

\begin{tabular}{ll}
\hline \hline Aim of pilot & Goal of specific project that will render new information, e.g. \\
project & ${ }^{*}$ develop urine processing unit \\
& * gain experience with peak shaving \\
& * receive a fertilizer allowance \\
& ${ }^{*}$ sociological research concerning user behavior in households \\
& establish causal relationships between e.g. user acceptance and information \\
\hline Early & Sketch out all involved parties: How can they be involved? e.g. \\
involvement & ${ }^{*}$ " politicians, wastewater authorities \\
& ${ }^{*}$ owners, architects, builders, plumbers \\
& ${ }^{*}$ users of NoMix toilets (e.g., information material, information events) \\
& ${ }^{*}$ scientists \\
& Define contact person in case of malfunctioning \\
\hline Legal & Approval of NoMix pilot project by wastewater authorities \\
aspects & Maybe approval by politicians \\
& Contracts: financial liability in case of malfunctioning, hazards, toilet replacement \\
& Contracts: tenants agree to live with drawbacks of NoMix toilets and research \\
& Fertilizer allowance to use urine-product in agriculture \\
\hline \hline
\end{tabular}

In institutions, a positive attitude of caretakers and cleaning personnel is crucial. It is important to have a clearly defined contact person who quickly takes care of things with good humor in case of complaints. Because these people will be far more strongly involved than the top management or even users of NoMix toilets, we recommend that they participate in decision-making from the start. Our surveys indicate that users of NoMix technology in public places show much goodwill, if the sanitary installations are well-maintained: $78 \%$ of users at Eawag and in the college found that design and smell of NoMix toilets equals conventional toilets, and $84 \%$ the hygiene (9). Occasional complaints in institutions were mostly caused by poor maintenance. However, early information and involvement of employees and visitors in institutions will never be wrong.

Legal Aspects. In many countries, NoMix pilot projects need legal approval. In Switzerland, the cantons must install municipal sewers and central treatment plants (17-18). Moreover, houses near existing municipal sewers must be connected. Exceptions to central wastewater treatment are possible in remote areas if water pollution control is ensured. In reality, 97\% of houses were connected to treatment plants in 2005 (19). Human urine was so far regarded as wastewater, but lacks specific mentioning in the Swiss law. Additionally, in the library project, politicians of canton Basel-Landschaft gave final approval for the NoMix technology after evaluation by an advisory commission. This could easily have stopped the project, however, once political support is granted, chances of success are higher.

Security aspects and financial liability in case of malfunctioning or hazards should be regulated with contracts between the major stakeholders. For instance, in our household project, toilet replacement was financed by the housing estate. However, it could also be the contribution of the wastewater authorities to support the innovative project. In future, we would always ask tenants for their written consent that they are willing to live with the drawbacks of NoMix toilets and that they know what associated research entails.

Usage of Urine. In many European countries, a fertilizer allowance is necessary for agricultural application of urine; a procedure we have just run through for the library. In Switzerland, fertilizers are listed in the "fertilizer book regulation" (20); some do not need allowance (mineral single- and multi-nutrient fertilizers), others do (e.g., organic fertilizers, manure), or are forbidden (e.g., containing blood and bone meal). Human urine is not listed and needs approval by the Swiss Federal Office for Agriculture (application details: 21). For instance, the fertilizer has to be suited for the intended application (i.e., urine fertilizers may need agricultural testing; 22), and no "unacceptable side-effects" for humans, animals, and the environment are allowed. We received a 
provisional allowance, exclusively for the specified urine treatment in the library. For a permanent allowance, we must provide evidence that the fertilizer is hygienically safe and does not contain micropollutants. The ecotoxicological approach of Novaquatis (16) and the multi-barrier concept of urine treatment (electrodialysis and ozonation; 15) were principally seen as good concepts. Initially, it could be easier to receive a fertilizer allowance for non-agricultural application, e.g., for football lawns or flower production.

This procedure is complicated and slow. However, we need a cautious approach to introduce a urine fertilizer to Swiss agriculture, where the use of sewage sludge was banned in 2003, mainly because of skepticism due to food scandals (genetically modified seed, BSE; 23). Similarly, in 1999, the Federation of Swedish Farmers (LRF) recommended its members to stop using sludge, resulting in only $10 \%$ being recycled to agriculture in 2001 (24). Our research showed that Swiss farmers (25) and consumers (7) are favorable towards urine-based fertilizers, but critical regarding possible contaminants.

The "Ecosan-community" has frequently discussed whether urine should be treated to remove micropollutants. We think that this decision is up to each country. Evidence from natural science regarding hazards from micropollutants in agriculture is still scant; therefore, in Switzerland we follow the precautionary principle.

\section{Technological Aspects of Buildings and Sanitary Installations}

NoMix Toilets and Waterfree Urinals. Sweden is certainly European pioneer and re-introduced NoMix toilets in the 1970ies to solve sanitation problems of remote holiday houses (26). Modern NoMix toilets were produced by small Swedish firms and installed in many pilot projects from the 1990ies on (1). To date, over 135,000 urine-diverting toilets have been installed in Sweden (27). Despite this broad application, all NoMix toilets still have problems. The most serious drawback is scaling, which leads to blockages of urine-conducting pipes (Fig. 2). Precipitation was extensively studied in Novaquatis (10-11). We now better understand the mechanisms; however, the sanitary industry needs much ingenuity to find elegant solutions. NoMix toilets also have some designrelated problems.

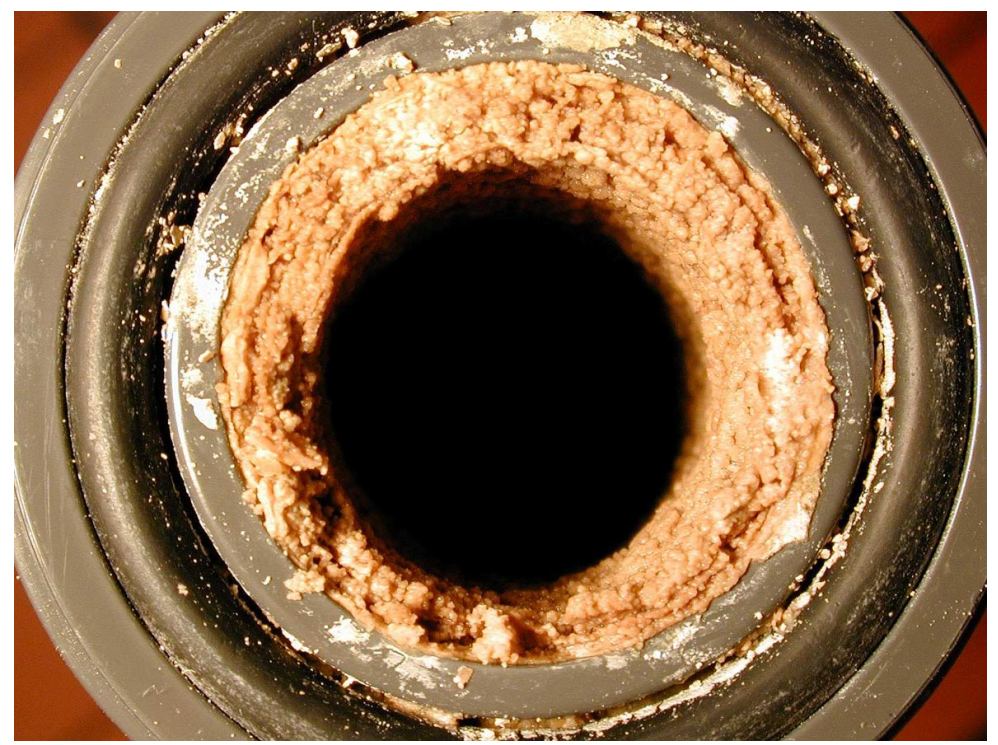

Figure 2. Scaling in urine-conducting pipes leading to blockages. This is one of the most severe problems of NoMix toilets. The build-up of precipitates can be slowed down already when building a pilot project, for instance by installing urine-conducting pipes with a slope and large diameter. A further preventive measure is regular flushing, e.g., with citric acid $10 \%$. Blockages can be removed with strong acid or caustic soda, or mechanically, e.g., with steel brushes. Photo: Kai Udert, 2002. 


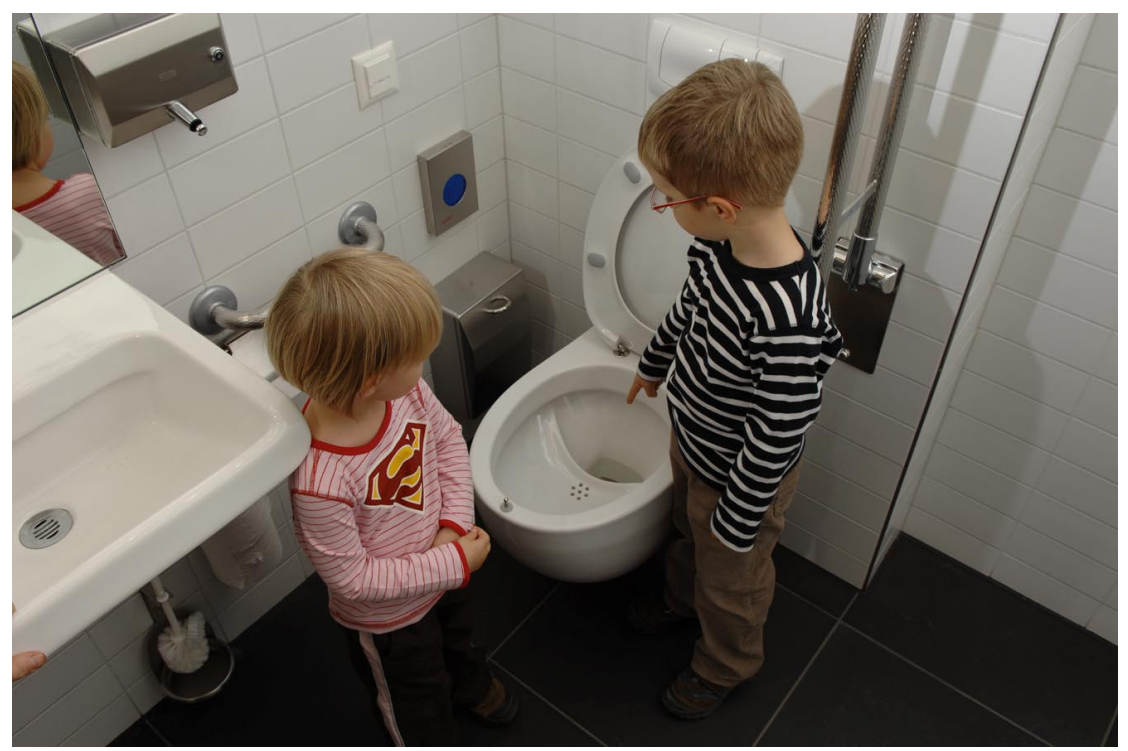

Figure 3. How does a NoMix toilet work? NoMix toilets allow separate collection of urine, which can be stored in a tank in the cellar. The urine is drained off in the front bowl; the rest reaches the sewers as in any toilet. In principle, NoMix toilets can be used like conventional toilets - if one sits to urinate. However, especially children may have problems with the proper sitting position. This model is by Roediger (www.roevac.com). Photo: Ruedi Keller, 2006.

Flushing System. Two types of water-flushed NoMix toilets are available (Fig. 3; Tab. 2). The earlier models (www.dubbletten.nu) flushed the front urine compartment with very little water (8 $\mathrm{ml}-1.5 \mathrm{dl}$ ). Hence, water can be saved if toilet paper is disposed of in a separate bin after urinating. If the paper is flushed away with the large flush, even more water could be consumed than with conventional dual-flush toilets, depending on how many users adopt this behavior. At Eawag, 58\% of users disposed of the paper in a bin after urinating (9). The more recently developed NoMix toilets use the same dual-flush system as any other modern toilet $(2-3 / 6-7 \mathrm{~L})$. Nonetheless, little flushing water (2.5 dl; www.gustavsberg.com); or none (Roediger: www.roevac.com) reaches the urine tank. Earlier models by Wost-Man-Ecology in our first pilot project functioned like Gustavsberg toilets. On the present homepage (www.wost-man-ecology.se), a system is described that seems to work like Dubbletten.

Non-diluted urine is advantageous for further treatment and requires a smaller storage tank. To this end, Roediger invented a closing mechanism for the urine drain, which only opens, when one sits. However, it is a disadvantage that one has to fully sit to urinate - for men, but also for women in public places. In our surveys, $75 \%$ of women were willing to sit on public NoMix toilets; the most promising measures to increase this number were good information and hygiene (9).

Of course, it is not necessary to use drinking water for flushing. Simulations showed that flushing with soft water, (e.g., rain) strongly reduces the precipitation potential of urine compared with tap water, thus reducing the risk of blockages (10). An often heard myth is that if urine is not diluted with water, no precipitation occurs. This is not supported by any scientific evidence. On the contrary, urine dilution reduces blockages, since the mass concentration of precipitates decreases with water volume (11). Moreover, recycled water or grey water could be used for flushing. In an Eawag pilot project, a membrane bioreactor was installed in the cellar and recycled wastewater used for toilet-flushing (28). This technology needs improvement because yellow coloring of water resulted in double-flushes and more frequent cleaning.

Design. We do not prefer a NoMix toilet model; the main differences concern the flushing system and design (Tab. 2). The front bowl of Roediger toilets seems to take up too much space, some women reporting that they had to sit too far to the back. If people sit too far to the front while 
Table 2. Overview of building aspects. These should be considered before building a NoMix pilot project; they concern the choice of sanitary installations, building requirements to avoid scaling of urine-conducting pipes and requirements of tanks, transport, processing, and research. Details concerning answers in text.

\begin{tabular}{|c|c|}
\hline \multirow{5}{*}{$\begin{array}{l}\text { Flushing } \\
\text { system } \\
\text { NoMix toilets }\end{array}$} & Is water saving a goal? \\
\hline & Would people use separate bin for disposal of urine-soiled paper? \\
\hline & Is it problematic if urine in tank is diluted with flushing water? \\
\hline & Would users fully sit to urinate? \\
\hline & Could rain or recycled wastewater be used? Is colored recycled water problematic? \\
\hline \multirow{3}{*}{$\begin{array}{l}\text { Design of } \\
\text { NoMix toilets }\end{array}$} & Should users rather sit to back (stains by feces) or front (loss of urine)? \\
\hline & Do children use toilet? Children's seat available? \\
\hline & Floor-mounted model (renovations) / wall-mounted model (more modern) preferred? \\
\hline \multirow{2}{*}{$\begin{array}{l}\text { Waterfree } \\
\text { urinals }\end{array}$} & Many models; overview on ecosan/GTZ homepage (29) \\
\hline & Efficient ventilation (e.g., ventilating air from ceiling downwards) \\
\hline \multirow[t]{3}{*}{$\begin{array}{l}\text { Scaling of } \\
\text { pipes }\end{array}$} & $\begin{array}{l}\text { When building: remember to keep retention time of urine short, e.g. with: } \\
\text { * slope of pipes (>2-3\%, preferably } 5 \%) \\
\text { * avoid tight angles } \\
\text { * wide diameter of pipes (> } 65 \mathrm{~mm} \text {, preferably } 75-110 \mathrm{~mm} \text { ) } \\
\text { * all parts easily accessible and removable (e.g., screw fittings, cleaning apertures) }\end{array}$ \\
\hline & Material: watertight, resistant to urine, strong acids, $\mathrm{NaOH}$, non-corrosive, etc. \\
\hline & Material: prevention of biofilm formation: silver-doped glazes, maybe lotus surfaces \\
\hline \multirow{11}{*}{$\begin{array}{l}\text { Urine storage } \\
\text { tanks, } \\
\text { transport }\end{array}$} & Material: as pipes \\
\hline & Outdoors: buoyancy due to ground water? Use glass-reinforced plastic \\
\hline & Avoid loss of ammonia / indoors avoid smell (e.g., odor trap) \\
\hline & Space requirements: $10 \mathrm{~L}_{\text {toilet }}^{-1}$ to $300 \mathrm{~L}_{\text {person }}{ }^{-1}$ depending on goal \\
\hline & Overflow outlet (e.g., into sewers) / Drip pan on floor in case of spills \\
\hline & Stirring mechanism to avoid urine sludge / possibility to empty \& clean tank (manhole) \\
\hline & Connection piece and pump for transport by truck \\
\hline & Electronic real-time control for peak shaving? \\
\hline & Urine sampling points? \\
\hline & Disconnection of pipes from tank to avoid contamination when pipes are flushed \\
\hline & Ventilation system if near people (offices etc.) \\
\hline Processing & Specific requirements of chosen process technology (see 13-15 and www.huber.de) \\
\hline Research & What do we want to learn? What technical installations does this entail? See text \\
\hline
\end{tabular}

defecating, increased cleaning is needed to remove feces. In contrast, the other models have a narrow front part, potentially resulting in loss of urine. However, we did not find a statistically significant difference in sitting behavior between these two toilet types (9). Unfortunately, children have a real positioning problem (Fig. 3). Here, a solution is required for Roediger toilets, while e.g. Dubbletten offers a children's toilet seat. For further information see the producers' homepages (overview: 29).

Waterfree urinals. These are a simple way of collecting urine from men in public places. Waterfree urinals save much water and are widely installed for economic reasons. The growing market and competition among manufacturers ensures a wide variety of models and continuous improvement (overview: 29). Here, main points to consider are odor problems (various stench traps are used), and urine stains, which necessitate regular cleaning and sometimes special cleansing or coating agents. Scaling is usually less problematic than in NoMix toilets, because it mainly occurs in the exchangeable traps (Fig. 4). Because of occasional complaints of bad odor from urinals (rarely from NoMix toilets), we recommend installing an efficient ventilation system. 


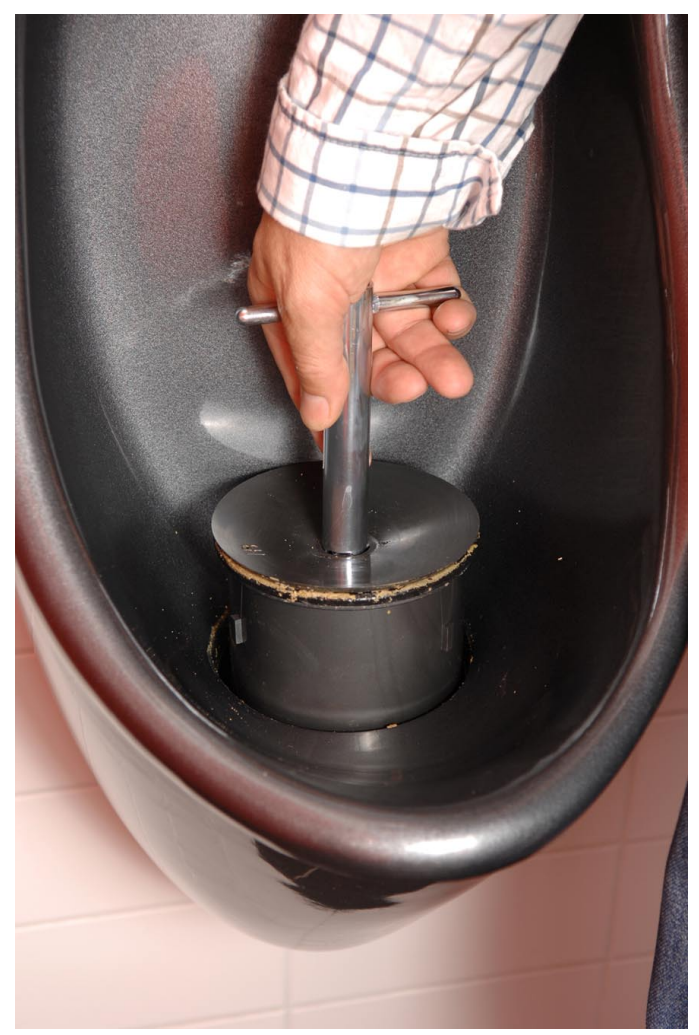

Figure 4. Removal of precipitates in waterfree urinals. All NoMix installations need very good cleaning and maintenance. Some waterfree urinals require regular exchange of the stench trap. Future developments of NoMix toilets by the sanitary industry could involve a similar solution: Controlled precipitation of struvite could be provoked in the NoMix toilets. This would not only minimize blockages, but could be an elegant way to recover phosphorus for fertilizer use. This urinal is by Hellbrok (www.hellbrok.com). Photo: Ruedi Keller, 2006.

Scaling of Urine-Conducting Pipes. A main consideration of urine pipe installation is to avoid and enable removal of blockages (Fig. 2). Urea-positive bacteria that are present in any sanitary system trigger urea hydrolysis, which leads to scaling (11). Hard-scale precipitates in urine pipes eventually lead to blockages. Sludge is usually found in the bottom of urine storage tanks, but can easily be removed. Scaling problems require unconventional solutions from builders and plumbers, since optimized hydraulic conditions strongly diminish precipitate formation (11). A main objective is a short retention time of urine, which requires sloping, well-accessible pipes with wide diameters (overview: 11, 29; Tab. 2).

Precipitates contain nutrients, struvite dominating in low diluted urine, and calcite in urine highly diluted with drinking water (11). These nutrients are lost for recycling. However, this could be used for advanced solutions of fertilizer production: Controlled precipitation of struvite could be provoked in exchangeable traps in NoMix toilets, similar to those in waterfree urinals. This would minimize blockages and might be an elegant way to recover phosphorus (Fig. 4).

Urine Storage Tanks, Transport, and Processing. Material requirements of storage tanks are the same as of pipes (overview: 29; Tab. 2). If the tank is buried outdoors, buoyancy due to ground water must be considered. Ammonia losses should be avoided. Nonetheless, we found that bad odor is nearly inevitable near urine storage tanks. Hence, indoors good ventilation must be assured. We also received occasional complaints of bad odor from users of Roediger NoMix toilets when the urine outlet opened, indicating possible ammonia losses in the piping system (12). Therefore, an odor trap between pipes and tank might be a good idea. 
The tank size depends on its purpose. Suggestions range from $10 \mathrm{~L}^{\text {toilet }}{ }^{-1}$ for peak shaving (30) to Swedish recommendations to store urine for 6 months for hygienization and subsequent use in agriculture (26). This results in a tank size of nearly $300 \mathrm{~L}^{\text {person }}{ }^{-1}$. Generally, one assumes a urine production of ca. $1.5 \mathrm{~L}_{\text {person }}{ }^{-1}$ day $^{-1}$ plus flushing water $\left(0-2.5 \mathrm{dl} \mathrm{flush}{ }^{-1}\right)$. However, in households (Roediger), we only collected $0.84 \mathrm{~L}_{\text {person }}{ }^{-1}$ day $^{-1}$ (average $0.14 \mathrm{~L} \mathrm{flush}^{-1}$, six toilet uses day ${ }^{-1}$ ), albeit with large variations between apartments (12). Swedish results with Dubbletten toilets are similar: 0.61-1.09 $\mathrm{L}_{\text {person }}{ }^{-1}$ day $^{-1}(31)$. More urine can be collected with waterfree urinals: $225 \mathrm{ml}$ usage $^{-1}$ at Eawag (12). Overall, we expect ca. $70-75 \%$ urine recovery.

Future development will aim at increasing recovery. Like in conventional wastewater treatment, realistic simulations help estimating optimal tank size. If urine is collected by truck, remember special occasions like Christmas. However, for research purposes there is no need to always be on the safe side if alternatives are available: The tank must be equipped with an overflow outlet, e.g., into sewers (more suggestions in: Tab. 2). Finally, if urine is processed, requirements of the treatment technology must be considered. Currently, only one urine processing technology is commercially available: the recovery of phosphate by struvite precipitation (www.huber.de (desar)). All other technologies are in a pilot stage (details in: 13-15).

\section{Acquisition of Information}

A pilot project is conducted to gain information and is often accompanied by research. This might entail planning installations beforehand. The more information and flexibility required, the higher the costs.

Pipes and Tanks. At Eawag, because of research with micropollutants, we installed separate storage tanks for women and men (hardly any female hormones). For urine processing, we need fresh urine before hydrolization and installed a sampling point to retain $2.9 \mathrm{~L}$ fresh urine. Sampling points were also installed shortly before urine reaches the tank and at three different tank levels. In the first Eawag pilot project, we frequently received complaints of bad smell from the nearby offices whenever we collected urine. Therefore, the tank should have a very efficient ventilation system. The Eawag tanks are equipped with $\mathrm{pH}$ meters and electronic control units for tank emptying and monitoring of tank filling. Moreover, we found that the tank shape was not suited to record fill levels; for this the tank should be as slim as possible (12). We installed data loggers to register the number of usages of NoMix toilets in earlier pilot projects. In the new Eawag building such data can be directly transmitted to computers with (costly) electronic equipment.

Sociological Research. In social science studies, one might want to test acceptance of different NoMix toilets or waterfree urinals (e.g., among different user groups), which must be installed beforehand. Or one could install a measuring device to register the number of users that sit to urinate.

A main problem with our exploratory questionnaire surveys was that causal relationships cannot be established. For instance, we found a statistically significant higher acceptance of NoMix toilets among people that generally like the idea of urine separation. However, it is uncertain, whether the "nice NoMix toilet" enhanced this positive attitude, or whether an initially positive attitude towards urine separation increased the acceptance of NoMix toilets as sanitary devices (9). To establish causal relationships, controlled experiments are needed. Hence, further sociological research could focus on finding explanatory variables that increase acceptance or the behavior required by NoMix toilets such as sitting to urinate. We also found a strong positive relationship between acceptance and information. We further found that discussions about NoMix toilets with colleagues were significantly correlated with a positive attitude, and we suggested that in future pilot projects, information events could be a useful measure. To establish, whether this indeed increases acceptance, controlled intervention studies are needed, where one group of people "knows nothing" about NoMix toilets, the other receives additional information, and the third has the opportunity to communicate with peers. 
Table 3. Overview of cleaning and maintenance aspects. These should be considered when running a NoMix pilot project; they can be crucial for its success.

\begin{tabular}{ll}
\hline \hline $\begin{array}{l}\text { Cleaning and } \\
\text { maintenance }\end{array}$ & In public buildings: at least 1-2x day-1 \\
& $\begin{array}{l}\text { In private apartments: are tenants aware of required maintenance? } \\
\text { Good cleaning / maintenance: } \\
\text { * avoids smell, urine drops, blockages } \\
\text { * increases number of people willing to adopt appropriate behavior (e.g., sitting) } \\
\text { Define contact person in case of malfunctioning }\end{array}$ \\
\hline $\begin{array}{ll}\text { Waterfree } \\
\text { urinals }\end{array}$ & Regular exchange of barrier liquid and stench traps \\
& Hire maintenance service? \\
\hline $\begin{array}{l}\text { Blockages } \\
\text { due to }\end{array}$ & Regular flushing of urine-pipes (e.g., citric acid 10\% / hydrochloric acid 7\%) \\
scaling & Removal: caustic soda (NaOH) or strong acid \\
& Removal: steel brushes, plumbers snake, jet cleaning \\
\hline \hline
\end{tabular}

The perhaps most important gap in our own research on NoMix acceptance is our lack of quantitative household studies. People seem reluctant to accept increased maintenance in private homes (7), but this needs verification in larger surveys. Moreover, up to $50 \%$ of urine will be lost, if men are unwilling to sit to urinate at home. We strongly recommend that future research focuses on such sociological studies; examples can be found in the literature (references in: 9).

\section{Cleaning and Maintenance}

From a user point of view, good maintenance is the most important aspect to guarantee the success of NoMix pilot projects (Tab. 3). Daily cleaning of waterfree urinals helps avoiding odor and urine stains. Clean NoMix toilets increase the number of people willing to sit to urinate in public places (9), and maintenance helps avoiding blockages. If caretakers and cleaners consider the pilot project as "their" project, failures are less likely; early participation helps to achieve this.

Urinals. Initially, we sometimes received negative feedback concerning the three waterfree urinals at Eawag, caused by unpleasant odor and aesthetically unpleasant urine stains (Tab. 3). On several occasions, the barrier liquid was not exchanged, resulting in major blockages. Most urinal manufacturers give maintenance recommendations, which should be followed. Some also offer a maintenance service themselves or through a local plumber (e.g., www.ernstsystems.com, www.urimat.com, www.uridan.com). However, exchange of stench trap or barrier liquid is usually easy (Fig. 4). In a larger study in London no user adversely mentioned the waterless urinals; the operational staff even preferred them to flushing types because cleaning and maintenance was easier (32). At Eawag, because urine is used for research, water and cleansing products are unwanted. Therefore, urinals and NoMix toilets are cleaned with a microfibre-cloth and acetic acid.

Blockages. In Sweden, $96 \%$ of NoMix toilets had blockages after $<4000$ usages, $77 \%$ were caused by hair or toilet brush bristles and could easily be removed. Severe blockages through scaling also occurred (1). Similarly, at Eawag blockages by hair, toilet paper, or cigarettes were initially frequent. With increasing usages, blockages through scaling increased (Fig. 2). The Wost-ManEcology toilet had very frequent blockages with 29,139 usages and was removed in 2003 after total obstruction. The Dubbletten toilet was blocked three times after nearly 6000 usages. From 2003 on, we flushed urine drains every 1-3 weeks with $1 \mathrm{~L}$ hydrochloric acid $\left(2 \mathrm{Mol} \mathrm{L}^{-1}\right.$, ca. $7 \%$ ), followed by 2-3 L of cold tap water (Tab. 3). No more blockages occurred thereafter.

In the households, we asked tenants to regularly flush the urine drain with $1 \mathrm{dl}$ citric acid $10 \%$ followed by normal flushing while pressing down the Roediger toilet seat to open the outlet. This also helped preventing occasional odor from NoMix toilets. We speculate that odor complaints were caused by scaling around edges of the moveable plug, thus preventing its tight closure. 
Blockages can be removed with caustic soda or strong acid; however, this can attack copper pipes (review in: 11; Tab. 3). They can be removed mechanically, which roughens the surface, or by jet cleaning. Blocked parts of pipes or siphons (Fig. 4) could be exchanged.

Principal Considerations. It seems contradictory to introduce an environmentally friendly technology that necessitates usage of acid for failure-free functioning. However, in the pilot stage, small amounts of diluted acid do not pose any environmental or resources problem. We emphasize that an early technology cannot equal a well established technology with a century of experience. On this occasion we thank the sanitary firms, who made experimentation possible. The small Swedish firms are the real pioneers, investing into early NoMix prototypes. Roediger then entered the next stage of technology development. Following the theory of diffusion of innovations (5), large sanitary firms should now further improve NoMix toilets, thus enabling their wide-spread distribution (6).

\section{Costs of NoMix Technology}

Currently, costs of urban NoMix pilot projects are always higher than for conventional installations. The sanitary technology is often more expensive and singular solutions may be required. Special installations for research further increase costs. Urine treatment does not even exist yet and necessitates constructing prototypes. Pilot projects in existing buildings are more expensive than in new ones. For the latter, we recommend including NoMix installations in the general price quote, so that builders have an own motivation to minimize costs. For these reasons, and because we do not want to set a far too high standard, we will not reveal our expenses in existing pilot projects. Prices of sanitary installations, pipes, and tanks are given on producer's homepages (overview: 29). However, costs would decrease rapidly, once NoMix technology is produced for a larger market, as already happened with waterfree urinals.

\section{CONLUSIONS}

Based on our experience, installing NoMix toilets in public buildings is well possible, if the responsible caretakers are aware that they need increased cleaning and maintenance. In contrast, Novaquatis cannot generally recommend installing NoMix technology in private, urban homes, because of drawbacks regarding usage and maintenance compared to conventional sanitation. Installing NoMix toilets in households is possible, if the tenants are carefully informed about drawbacks and agree to live with them. Such projects should be accompanied by sociological research, because many questions remain unanswered for households. To ensure success, pilot projects must have clear goals, early stakeholder participation is mandatory, and projects should ideally be supported by wastewater authorities.

NoMix technology could induce a paradigm change in urban wastewater management, focusing on source control and nutrient recycling. Because application in quite different scenarios is possible (4), NoMix technology could also strongly increase the systems' flexibility. This is discussed elsewhere. However, for further technology development, it is necessary to carry out pilot projects. These are, unfortunately, expensive, complicated, and risky; a larger risk being that people gain a negative attitude, because NoMix technology does not yet equal modern sanitation standards. Negative experience and low acceptance at an early stage of technology introduction can bring an innovation to a total halt. With this paper we wish to share our experience with other wastewater professionals. We want to support researchers and practitioners to avoid the most serious pitfalls when carrying out NoMix pilot projects and hope that we can contribute to increased interaction between research and real-world application of this innovation. 


\section{ACKNOWLEDGEMENTS}

We thank the pilot projects, the caretakers and cleaning personnel, and especially the users of NoMix toilets for giving us a unique opportunity for real-word research: (1) Eawag, (2) housing estate with NoMix toilets, (3) college, Claude Lüscher, and Maximilian Mayer from the University of Applied Sciences Northwestern Switzerland, and (4) cantonal library Basel-Landschaft in Liestal, Geri Koch, and "Amt für Industrielle Betriebe Basel-Landschaft” (AIB).

\section{REFERENCES}

1. Hellström, D. and Johansson, E. 1999. Swedish experiences with urine separating systems, Wasser \& Boden 51(11), 26-29.

2. Otterpohl, R., Albold, A. and Oldenburg, M. 1999. Source control in urban sanitation and waste management: Ten systems with reuse of resources. Water Sci. Technol., 39(5), 153-160.

3. Larsen, T. A., Peters, I. Alder, A., Eggen, R. I., Maurer, M. and Muncke, J. 2001. Re-engineering the toilet for sustainable waste water management. Environ. Sci. Technol., 35(9), May1, 192A-197A.

4. Larsen, T. A., Maurer, M., Udert, K. M. and Lienert, J. 2007. Nutrient cycles and resource management: implications for the choice of wastewater treatment technology. Water Sci. Technol., 56(5) 229-237.

5. Rogers, E. M. 1983. Diffusion of Innovations. $5^{\text {th }}$ ed., Free Press, New York, 551 pp.

6. Larsen, T. A. and Lienert, J. 2003. Societal implications of re-engineering the toilet. Water Intelligence Online, March 2003. UNIQUE ID: 200303006. www.iwaponline.com/wio/2003/03/default001.htm

7. Pahl-Wostl, C., Schönborn, A., Willi, N., Muncke, J. and Larsen, T. A. 2003. Investigating consumer attitudes towards the new technology of urine separation. Water Sci. Technol., 48(1), 57-65.

8. Lienert, J., Thiemann, K., Kaufmann-Hayoz, R. and Larsen, T. A. 2006. Young users accept NoMix toilets - A questionnaire survey on urine source separating toilets in a college in Switzerland. Water Sci. Technol., 54(11-12), 403-412.

9. Lienert, J. and Larsen, T. A. 2006. Considering user attitude in early development of environmentallyfriendly technology: A case study of NoMix toilets. Environ. Sci. Technol., 40(16), 4838-4844.

10. Udert, K. M., Larsen, T. A., Biebow, M. and Gujer, W. 2003a. Urea hydrolysis and precipitation dynamics in a urine-collecting system. Water Res. 37(11), 2571-2582.

11. Udert, K. M., Larsen, T. A. and Gujer, W. 2003b. Biologically induced precipitation in urine-collecting systems and urinal traps. Water Sci. Technol.: Water Supply 3(3), 71-78.

12. Rossi, L., Lienert, J. and Larsen, T.A. In preparation. Real-Life efficiency of urine source separation: experience from households and an institution.

13. Maurer, M., Pronk, W. and Larsen, T. A. 2006. Review: Treatment processes for source separated urine. Water Res. 40(17), 3151-3166.

14. Pronk, W., Biebow, M. and Boller, M. 2006. Electrodialysis for recovering salts from a urine solution containing micropollutants. Environ. Sci. Technol. 40(7), 2414-2420.

15. Pronk, W., Zuleeg, S., Lienert, J., Escher, B., Koller, M., Berner, A., Koch, G. and Boller, M. 2007. Pilot experiments with electrodialysis and ozonation for the production of a fertilizer from urine. Accepted for publication in Water Sci. Technol., 56(5), 219-227.

16. Escher, B. I., Pronk, W., Suter, M. J.-F. and Maurer, M. 2006. Monitoring the removal efficiency of pharmaceuticals and hormones in different treatment processes of source-separated urine with bioassays. Environ. Sci. Technol. 40(16), 5095-5101.

17. Gewässerschutzgesetz (Swiss water pollution control bill): Bundesgesetz über den Schutz der Gewässer. 24.01.1991. SR-Number 814.20. Can be downloaded at: http://www.admin.ch/ch/d/sr/c814 20.html, last visit to website: 07.06.2006, email: webmaster@admin.ch, (in German).

18. Gewässerschutzverordnung (Swiss water pollution control regulation). 24.10.1998. SR-Number 814.201. Can be downloaded at: http://www.admin.ch/ch/d/sr/c814_201.html, last visit to website: 07.06.2006, email: webmaster@admin.ch, (in German). 
19. FOEN: Swiss Federal Office for the Environment. 1996. Homepage of Water Division Available at: http://www.umwelt-schweiz.ch/buwal/eng/fachgebiete/gewaesserschutz/abwasser/kommunal/index.html, last visit to website: 07.06.2006, email: wasser@bafu.admin.ch.

20. Düngerbuch-Verordnung (Fertilizer book regulation). 28.02.2001. SR-Number 916.171.1. Can be downloaded at: http://www.admin.ch/ch/d/sr/c916 171 1.html, last visit to website: 07.06.2006, email: webmaster@admin.ch, (in German).

21. Dünger-Verordnung (Fertilizer regulation). 10.01.2001. SR-Number 916.171. Can be downloaded at: http://www.admin.ch/ch/d/sr/c916_171.html, last visit to website: 07.06.2006, email: webmaster@admin.ch, (in German).

22. Simons, J. and Clemens, J. 2003. The use of separated human urine as mineral fertilizer. In: 'ecosan closing the loop' Proceedings of the $2^{\text {nd }}$ International Symposium on Ecological Sanitation, Lübeck 2003. Deutsche Gesellschaft für Technische Zusammenarbeit (GTZ) GmbH (ISBN 3-00-012791-7), 595-600.

23. Seyman, I. 2003. Sewage Sludge - No more land treatment in Switzerland. Hydroplus 135, 21.

24. Bengtsson, M. and Tillman, A. M. 2004. Actors and interpretations in an environmental controversy: the Swedish debate on sewage sludge use in agriculture. Resour. Conserv. Recycl. 42(1), 65-82.

25. Lienert, J., Haller, M., Berner, A., Stauffacher, M., and Larsen, T. A. 2003. How farmers in Switzerland perceive fertilizers from recycled anthropogenic nutrients (urine). Water Sci. Technol., 48(1), 47-56.

26. Johansson, M., Jönsson, H., Höglund, C., Richert Stintzing, A. and Rodhe, L. 2001. Urine separation closing the nutrient cycle. Final report on the R\&D project: Source-separated human urine - a future source of fertilizer for agriculture in the Stockholm region? VERNA Ecology \& Stockholm Water Company, Stockholm, 40 pp.

27. Kvarnström, E., Emilsson, K., Richert Stintzing, A., Johansson, M., Jönsson, H., af Petersens, E., Schönning, C., Christensen, J., Hellström, D., Qvarnström, L., Ridderstolpe, P. and Drangert, J.-O. 2006. Urine diversion: one step towards sustainable sanitation. EcoSanRes Publications Series Report 2006-1. http://www.ecosanres.org/news-publications.htm., 64 pp.

28. Abegglen, C., Böhler, M., Bützer, S., Joss, A. and Siegrist, H. In preparation. Reducing natural color of membrane bioreactor permeate with activated carbon or ozone (working title).

29. ecosan/GTZ. 2005. Technical data sheets for ecosan components. Draft versions available at: www.gtz.de/en/themen/umwelt-infrastruktur/wasser/9397.htm. Deutsche Gesellschaft für Technische Zusammenarbeit (GTZ) GmbH; ecological sanitation (ecosan). last visit to website: 07.06.2006, Contact person: Christine Werner, ecosan@gtz.de.

30. Rauch, W., Brockmann, D., Peters, I., Larsen, T. A. and Gujer, W. 2003. Combining urine separation with waste design: an analysis using a stochastic model for urine production. Water Res. 37(3), 681-689.

31. Jönsson, H., Vinnerås, B., Höglund, C. and Stenström, T.-A. 1999. Source separation of urine (Teilstromerfassung von Urin). Wasser \& Boden 51(11), 21-25.

32. Hills, S. and Birks, R. 2004. Washroom behaviour and users' perceptions of "novel" water-efficient appliances. Water Sci. Technol.: Water Supply, 4(3), 13-23. 